\title{
Polarization of $\mathrm{TH} 2$ response is decreased during pregnancy in systemic lupus erythematosus
}

\author{
L. laccarino', A. Ghirardello', M. Zen'1, D. Villalta ${ }^{2}$, A. Tincani ${ }^{3}$, L. Punzi', A. Doria ${ }^{1}$ \\ 'Division of Rheumatology, Department of Medicine, University of Padova, Italy; \\ ${ }^{2}$ Hospital S. Maria degli Angeli, Pordenone, Italy; \\ ${ }^{3}$ Rheumatology and Clinical Immunology, Spedali Civili and University of Brescia, Brescia, Italy
}

Work awarded at XLVIII Congress of Italian Society of Rheumatology (SIR), Rimini 2011

\section{SUMMARY}

This study evaluated some cytokines involved in the Th1-Th2 shift during pregnancy in patients with systemic lupus erythematosus (SLE) and healthy women.

Twenty-seven consecutive successful pregnancies in 26 SLE patients and 28 pregnancies in 28 matched healthy subjects, as controls, were enrolled and prospectively studied. Sera obtained at first and third trimesters of pregnancy were tested for IL-1 $\alpha$, IL-1 $\beta$, IL-2, IL-6, IL-8, IL-10, IL-12p70, INF- $\gamma$, and TNF- $\alpha$ with a highly sensitive, multiplexed sandwich ELISA (SearchLight Human Inflammatory Cytokine Array). Statistics were performed by SPSS package. IL-8 serum levels were higher in the first $(\mathrm{P}<0.0001)$ and third $(\mathrm{P}=0.003)$ trimesters of pregnancy in SLE patients compared with controls, INF- $\gamma$ serum levels in the third trimester $(\mathrm{P}=0.009)$, and IL-10 serum levels in the first and third trimesters ( $\mathrm{P}=0.055$ and $\mathrm{P}<0.0001$, respectively). IL-2 ( $\mathrm{r}=0.524$ $\mathrm{P}=0.010), \mathrm{IL}-12$ ( $\mathrm{r}=0.549 \mathrm{P}=0.007), \mathrm{IFN}-\gamma(\mathrm{r}=0.492 \mathrm{P}=0.017)$, and IL-6 ( $\mathrm{r}=0.515 \mathrm{P}=0.020)$ serum levels correlated with disease activity in SLE patients in the first trimester of pregnancy. Cytokine profile was similar in patients with and without lupus nephritis both in the first and in the third trimesters of pregnancy. IL-8 serum levels were lower in patients with a previous diagnosis of antiphospholipid antibody syndrome compared with those without, both in the first and in the third trimesters of pregnancy.

In SLE patients, a lower than expected decrease in Th1 cytokine serum levels was observed in the third trimester of gestation which could contribute to a lower Th2 cytokine polarization during pregnancy.

Key words: Systemic lupus erythematosus, lupus pregnancy, lupus cytokines.

Reumatismo, 2012; 64 (5): 314-320

\section{INTRODUCTION}

ytokines produced by $\mathrm{CD} 4+$ helper

$\mathrm{T}(\mathrm{Th})$ cells are traditionally subdivided into Th1 and Th2. Th1 cytokines stimulate cellular immunity and include interferon (IFN)- $\gamma$, interleukin (IL)- 1 , IL2, IL-8, IL-12, and tumor necrosis factor (TNF)- $\alpha$. Th2 cytokines induce humoral immunity and antibody production, and include IL-4, IL-5, IL-6 and IL-10 (1). During pregnancy, important changes occur in the maternal immune and endocrine systems $(2,3)$. Maternal immune response is characterized by a Th 2 polarization that is driven by high levels of estrogens and progesterone (4-6).

In patients affected with systemic lupus erythematosus (SLE), an overproduction of Th2 cytokines that results in B-cell hyperactivity has been demonstrated (7). Therefore, it is expected that Th2 cytokine hyperpolarization will result in an increase in SLE complications, particularly in the third trimester of pregnancy when estrogens and progesterone are supposed to be at their highest levels (8). However, lower levels of estrogens, progesterone and Th2 cytokines were found in the third trimester of pregnancy in SLE patients compared with healthy pregnant women (9) and disease flare rate was similar in pregnant women compared with nonpregnant SLE patients in some case-control studies (9-11).

The purpose of this study was to evaluate Th1-Th2 profile in a cohort of patients affected with SLE during pregnancy. 


\section{PATIENTS AND METHODS}

Twenty-seven pregnancies in 26 SLE patients and 28 pregnancies in 28 healthy women, as controls, were prospectively evaluated. Only pregnancies ending with live births were included in the analysis. All patients fulfilled the 1997 American College of Rheumatology (ACR) classification criteria for SLE (12) and were followed-up at the Rheumatology Units of Rheumatology of the University of Padova and Brescia, Italy. All patients and controls signed written informed consent and the local ethics committees gave their approval for the study.

All patients underwent laboratory tests and rheumatology and gynecological visits every month during pregnancy and the postpartum period, as suggested for pregnancy monitoring in SLE (13). At baseline visit, before pregnancy, we assessed disease activity by ECLAM (European Consensus Lupus Activity Measurement) score (14). During pregnancy, we used the ECLAM score modified for pregnancy (15). Active SLE was defined by an ECLAM score of 2 or over.

\section{Cytokine assays}

Serum samples were collected for cytokine determinations at the first (9-11 weeks) and third (29-31 weeks) trimesters of gestation from SLE patients and healthy controls, and were stored in aliquots at $-80^{\circ} \mathrm{C}$ until analysis.

IL-1 $\alpha$, IL-1 $\beta$, IL-2, IL-6, IL-8, IL-10, IL$12 p 70$, IFN- $\gamma$ and TNF- $\alpha$ serum levels were quantitatively determined by a highly sensitive enzyme-linked sandwich immunosorbent assay (ELISA) designed with multiplex technology (Search Light Human Inflammatory Cytokine Array by Pierce Biotechnology, Rockford, IL, USA) (16). This was approved as a reference method for the quantitative determination of cytokines in human biological fluids by the US National Institute of Health (Bethesda, MD, USA). The assay procedure was performed according to the manufacturer's instructions.

Ranges of measurability of the standard curve for each cytokine tested were: IL$1 \alpha=0.78-200 \mathrm{pg} / \mathrm{mL} ; \mathrm{IL}-1 \beta=0.39-100 \mathrm{pg} /$
$\mathrm{mL}$; IL-2 $=0.78-200 \mathrm{pg} / \mathrm{mL}$; IL-6=0.78-200 $\mathrm{pg} / \mathrm{mL}$; IL-8 $=0.78-200 \mathrm{pg} / \mathrm{mL} ; \mathrm{IL}-10=0.78$ $200 \mathrm{pg} / \mathrm{mL} ; \quad \mathrm{IL}-12 \mathrm{p} 70=1.2-300 \mathrm{pg} / \mathrm{mL}$; IFN- $\gamma=0.78-200 \mathrm{pg} / \mathrm{mL} ;$ TNF- $\alpha=4.7-1200$ $\mathrm{pg} / \mathrm{mL}$. Analytical sensitivity was: IL$1 \alpha=0.4 \mathrm{pg} / \mathrm{mL} ; \mathrm{IL}-1 \beta=0.2 \mathrm{pg} / \mathrm{mL} ; \mathrm{IL}-2=0.4$ $\mathrm{pg} / \mathrm{mL} ; \mathrm{IL}-6=0.2 \mathrm{pg} / \mathrm{mL}$; IL-8 $=0.4 \mathrm{pg} / \mathrm{mL}$; IL-10=0.2 pg/mL; IL-12p70 $=0.4 \mathrm{pg} / \mathrm{mL}$; IFN- $\gamma=0.2 \mathrm{pg} / \mathrm{mL} ; \mathrm{TNF}-\alpha=1.6 \mathrm{pg} / \mathrm{mL}$.

\section{Statistical analysis}

Statistical analysis was performed using the SPSS 16.0 package. Since cytokine serum levels did not follow normal distribution, either in healthy controls or in SLE patients, a non-parametric statistical analysis was used (Wilcoxon's test for paired data and the Mann-Whitney U test). A P value $<0.05$ was considered significant.

\section{RESULTS}

The mean age of SLE patients at the time of diagnosis was $22 \pm 5.0$ years, range $13-31$ years, and at the time of conception mean age was $32.3 \pm 3.7$ years, range $26-38$ years. The mean disease duration at the time of conception was $9.70 \pm 5.9$ years, range 1-20 years. The mean age of healthy controls at the time of conception was $30.8 \pm 5.8$ years (range 21-37 years), matched with that of SLE patients.

There were no differences between the mean weight of babies born from SLE women and from healthy controls. In addition, the duration of pregnancy was similar in SLE patients and in controls.

The ECLAM score before pregnancy ranged from 0 to $6($ mean \pm SD $2.7 \pm 1.33$, median value 3 ), and during pregnancy $35 \%$ of patients had an active SLE. At the time of conception, hematologic, skin and joint involvements were the most frequent manifestations of SLE patients and about one-third of these patients had renal involvement. Clinical and laboratory features of the 26 SLE patients at the time of conception are reported in Table I.

During pregnancy, $81.4 \%$ of patients received corticosteroid therapy and the mean dose taken by the patients in the first, sec- 
Table I - Clinical and laboratory features at conception in 26 SLE patients.

\begin{tabular}{|l|l|}
\hline Clinical manifestations & Patients $\mathbf{n}$ (\%) \\
\hline Hematologic involvement & $23(85.5)$ \\
\hline Arthralgias and/or arthritis & $21(77.7)$ \\
\hline Skin manifestations & $8(29.6)$ \\
\hline Glomerulonephritis & $8(29.6)$ \\
\hline Serositis & $3(11.1)$ \\
\hline CNS involvement & $2(7.4)$ \\
\hline Laboratory findings & \\
\hline Anti-dsDNA Ab & $25(92.5)$ \\
\hline Anticardiolipin Ab & $15(55.5)$ \\
\hline Anti-SSA Ab & $13(48.1)$ \\
\hline Anti-U1RNP Ab & $6(22.2)$ \\
\hline LAC & $6(22.2)$ \\
\hline Double LAC + aCL Ab & $5(18.5)$ \\
\hline Anti-Sm Ab & $4(14.8)$ \\
\hline
\end{tabular}

SLE, systemic lupus erythematosus; CNS, central nervous system; hematologic involvement, excluding hemolytic anemia. Ab, antibody; anti-dsDNA $\mathrm{Ab}$, anti double-stranded-DNA antibody; LAC, lupus anticoagulant; aCL, anticardiolipin antibodies.

ond and the third trimesters of pregnancy was $5.47 \pm 4.26 \mathrm{mg} /$ day (range $0-15$ ), $5.61 \pm 4.10 \mathrm{mg} /$ day (range $0-15$ ), $5.92 \pm 4.60$ $\mathrm{mg} /$ day (range 0-18), respectively. Patients with active SLE received a higher median dose of prednisone than patients with inactive disease: $8.06 \mathrm{mg} /$ day (range 5-15) vs $4.6 \mathrm{mg} /$ day (range 0-14.3) $(\mathrm{P}=0.03)$. Furthermore, $48.1 \%$ of patients received hydroxychloroquine, $29.6 \%$ azathioprine, and $3.7 \%$ were therapy free.

\section{Cytokine serum levels}

Median cytokine levels in SLE patients and healthy controls in the first and third trimesters of pregnancy are reported in Table II.

Compared with controls, SLE patients had higher IL-10 serum levels in the first $(\mathrm{P}=0.055)$ and in the third $(\mathrm{P}<0.0001)$ trimesters of pregnancy, IL-8 serum levels in the first $(\mathrm{P}<0.0001)$ and third $(\mathrm{P}=0.003)$ trimesters (Fig. 1), and INF- $\gamma$ serum levels in the third trimester $(\mathrm{P}=0.009)$ (Fig. 2).

The following cytokine serum levels correlated with ECLAM score in SLE patients in the first trimester of pregnancy: IL-2 $\mathrm{r}=0.524, \mathrm{P}=0.010$; IL-12 $\mathrm{r}=0.549$, $\mathrm{P}=0.007 ; \mathrm{IFN}-\gamma \mathrm{r}=0.492, \mathrm{P}=0.017$; IL-6 $\mathrm{r}=0.515, \mathrm{P}=0.020$. Cytokine profile was similar in patients with and without lupus nephritis both in the first and in the third trimesters of pregnancy.

IL-8 serum levels were lower in patients with a previous diagnosis of antiphospholipid antibody syndrome compared with those without, both in the first (4.40 (range 1.00-10.750) vs 8.70 (range 4.0539.850) $\mathrm{P}=0.045$ ) and in the third trimester of pregnancy (1.90 (range 0.25-4.050) vs 6.40 (1.65-29.200), $\mathrm{P}=0.008)$.

There were no differences in cytokine serum levels among patients receiving lowdose and high-dose corticosteroid therapy in either the first or the third trimesters of gestation.

Furthermore, there were no differences in cytokine serum levels among patients treated with or without antimalarials or azathioprine.

Table II - Th1 and Th2 cytokine serum levels during pregnancy in 28 healthy women compared with 26 SLE patients. The median values $\left(25^{\text {th }}-75^{\text {th }}\right.$ percentile) are expressed in $\mathrm{pg} / \mathrm{mL}$.

\begin{tabular}{|l|l|l|l|l|l|l|}
\hline & \multicolumn{3}{|c|}{ Healthy women } & \multicolumn{2}{c|}{ SLE patients } & \\
\hline & $1^{\text {st }}$ trimester & $3^{\text {rd }}$ trimester & $\mathbf{P}$ & $1^{\text {st }}$ trimester & $3^{\text {rd }}$ trimester & $\mathbf{P}$ \\
\hline TNF- $\alpha$ & $11.0(5.8-26.9)$ & $7.6(4.5-15.0)$ & 0.003 & $13.5(6.5-38.9)$ & $18.2(6.8-36.5)$ & n.s. \\
\hline IFN- $-\gamma$ & $3.4(1.7-6.1)$ & $1.5(1.0-3.3)$ & 0.001 & $4.1(1.5-11.1)$ & $3.8(1.5-11.0)$ & n.s. \\
\hline IL-1 $\alpha$ & $1.5(0.4-2.9)$ & $0.9(0-2.2)$ & 0.003 & $1.0(1.0-6.9)$ & $1.2(0.4-4.6)$ & 0.044 \\
\hline IL-1 $\beta$ & $0.8(0.5-1.4)$ & $0.5(0.3-0.9)$ & 0.026 & $1.4(0.6-4.3)$ & $1.1(0.4-3.7)$ & n.s. \\
\hline IL-2 & $4.0(1.6-7.3)$ & $3.4(0.5-6.4)$ & 0.012 & $3.1(1.5-12.5)$ & $4.7(1.3-9.7)$ & n.s. \\
\hline IL-8 & $5.3(3.4-7.7)$ & $4.5(2.2-6.5)$ & n.s. & $14.2(7.0-43.3)$ & $12.2(4.3-45.7)$ & n.s. \\
\hline IL-12 & $4.5(2.0-9.1)$ & $3.0(1.5-7.2)$ & 0.016 & $6.0(2.0-20.8)$ & $4.1(2-25.5)$ & n.s. \\
\hline IL-10 & $1.3(0.8-3.1)$ & $1.0(0.4-1.7)$ & n.s. & $2.9(1.5-6.1)$ & $4.4(1.9-6.3)$ & n.s. \\
\hline IL-6 & $6.0(2.2-11.8)$ & $4.8(2.9-9.5)$ & n.s. & $6.3(3.5-24.5)$ & $9.4(3.0-25.3)$ & n.s. \\
\hline
\end{tabular}

SLE, systemic lupus erythematosus; TNF- $\alpha$, tumor necrosis factor alpha, IFN- $\gamma$, interferon gamma, IL, interleukin; ns, not significant. 


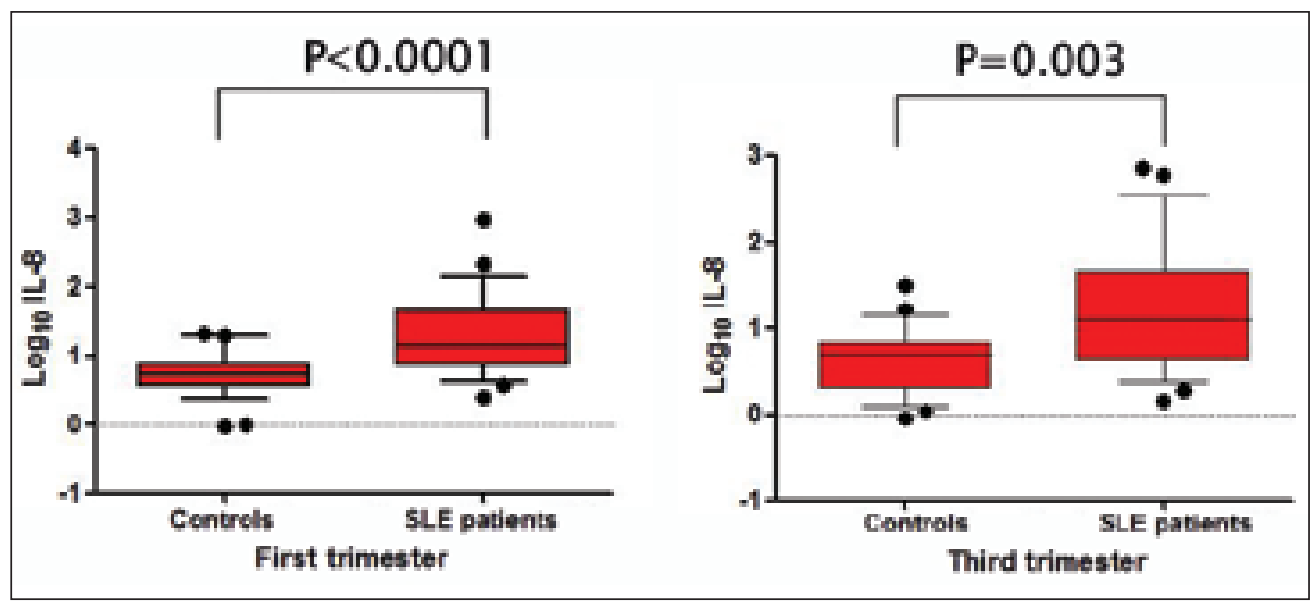

Figure 1 - IL-8 serum levels in controls and SLE patients in the first and third trimesters of pregnancy.

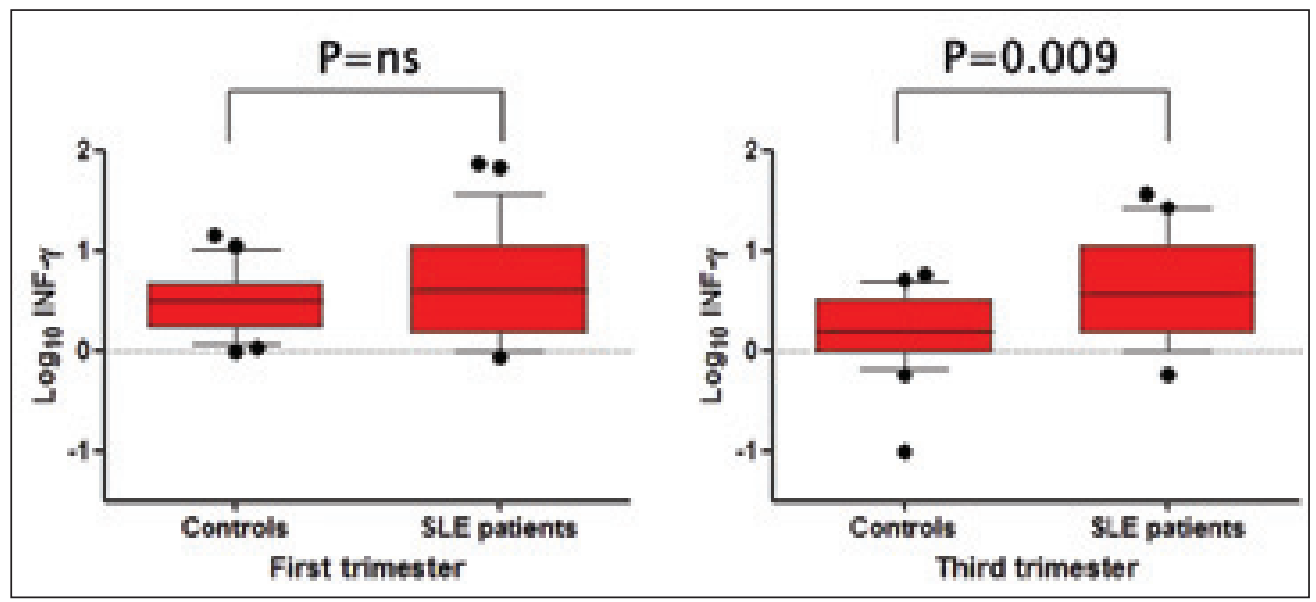

Figure 2 - IFN $\gamma$ serum levels in controls and SLE patients in the first and third trimesters of pregnancy.

\section{DISCUSSION}

During pregnancy, immune and endocrine systems undergo profound changes involving both hormones and cytokines: cortisol, progesterone, estradiol and testosterone physiologically increase during gestation and drive Th-2 cytokine polarization at the feto-maternal interface, as well as in systemic circulation. In fact, high levels of estrogens and progesterone inhibit Th1 type cytokine production from $\mathrm{T}$ cells (2) and stimulate the secretion of Th2 cytokines, including IL-4, IL-5, IL-6 and IL-10 (17-19), which lead to antibody production (20). Among Th2 cytokines, IL-6 stimu- lates the differentiation of Th0 cells toward a Th2 phenotype and inhibits the development of a Th1-mediated response (21); IL-10 stimulates B-cell proliferation, differentiation and antibody secretion (22). In addition, IL-10 inhibits antigen presenting cell and T-cell functions (22). High serum levels of IL-6 and IL-10 $(23,24)$ were observed in SLE patients and they correlated with disease activity or anti-double-stranded DNA antibodies (25-28).

The role of Th1 cytokines in the pathogenesis of SLE remains unclear. Probably there are differences between systemic and local effects of these cytokines. For example, some patients with rheumatoid arthritis 
who were treated with anti-TNF- $\alpha$ agents developed anti-double-stranded DNA antibodies and in some cases SLE or lupuslike disease (29). By contrast, the level of TNF $\alpha$ messenger RNA was high in kidneybiopsy specimens from patients with lupus nephritis (30) and TNF $\alpha$ expression was increased in skin biopsy specimens from patients with cutaneous SLE (31). Aringer et al. reported that the anti-TNF- $\alpha$ monoclonal antibody, infliximab, administered to 6 patients with lupus led to resolution of joint swelling in 3 patients with arthritis and the reduction of urinary protein loss by $60 \%$ in 4 patients with glomerulonephritis (32). Since Th2 cytokine production seems to play a key role in SLE, and an overproduction of IL- 6 and IL-10 is reported, we should expect a Th2 polarization of immune response in SLE patients compared with healthy controls, especially during pregnancy.

The most relevant features of our study were a lower than expected increase in Th2 cytokine during pregnancy in SLE patients and an increase in some Th1 cytokines, such as IL-8 and INF- $\gamma$, in SLE pregnant women compared with controls (Figs. 1 and 2). In our study, serum levels of Th2 cytokines were similar in SLE patients compared with controls and only IL-10 was higher in SLE patients than in healthy women. These data are comparable to those recently published by Torricelli et al. (33) who found higher serum levels of IL-10 in pregnant SLE patients compared with healthy pregnant women, and IL-10 serum levels progressively increased during pregnancy. Similarly, Muñoz-Valle et al. (34) showed higher levels of IL-10 in pregnant SLE patients than in healthy pregnant women, particularly during the last trimester of pregnancy. This lower than expected Th2 cytokine polarization may be explained by the lower levels of estrogen and progesterone that we found in a previous study in pregnant SLE patients compared with pregnant healthy women during the second and third trimesters of pregnancy (9). Furthermore, the lower Th2 polarization observed during pregnancy could explain why SLE flare rate was found to be similar between pregnant and non-pregnant patients in some controlled studies $(10,35,36)$.

The increased levels of IL- 8 and IFN- $\gamma$ in SLE patients compared with healthy pregnant women are unexpected. IL- 8 is a 8 $\mathrm{kDa}$ protein produced by many types of cells, not only monocytes, lymphocytes, granulocytes, fibroblasts and endothelial cells, but also trophoblast and placental macrophages (37) and IL-8 plays a key role in stimulation of trophoblast cell migration and invasion during pregnancy (38). By contrast, IFN- $\gamma$ and TNF- $\alpha$ that are produced in the deciduas are thought to act synergistically to inhibit trophoblast invasion (39). Furthermore, we found IL-8 serum levels lower in SLE patients with a previous diagnosis of antiphospholipid antibodies syndrome compared with those without, both in the first and in the third trimesters of pregnancy. Notably, it has been recently shown that anti- $\beta 2 \mathrm{GPI}$ antibodies could trigger an inflammatory response in trophoblast, (40) with an increased expression of Th1 cytokines, including IL-8. However, the reason why IL-8 serum levels were higher in SLE patients compared with controls, but were reduced in patients with antiphospholipid antibody syndrome remains to be clarified.

In conclusion, our study shows that in pregnant SLE patients the polarization towards Th2 cytokines is lower than expected and some Th1 cytokine serum levels are higher in SLE patients compared with healthy women.

\section{REFERENCES}

1. Romagnani S. The Th1/Th2 paradigm. Immunol Today. 1997; 18: 263-6.

2. Cutolo M, Sulli A, Seriolo B, et al. Estrogens, the immune response and autoimmunity. Clin Exp Rheumatol. 1995; 13: 217-26.

3. Zen M, Ghirardello A, Iaccarino L, et al. Hormones, immune response, and pregnancy in healthy women and SLE patients. Swiss Med Wkly. 2010; 140: 187-201.

4. Doria A, Iaccarino L, Arienti S, et al. Th2 immune deviation induced by pregnancy: the two faces of autoimmune rheumatic diseases. Reprod Toxicol. 2006; 22: 234-41. 
5. Lin H, Mosmann TR, Guilbert L, et al. Synthesis of $\mathrm{T}$ helper 2-type cytokines at the maternal-fetal interface. J Immunol. 1993; 151: 4562-73.

6. Rodriguez E, Guevara J, Paez A, et al. The altered expression of inflammation-related molecules and secretion of IL-6 and IL- 8 by HUVEC from newborns with maternal inactive systemic lupus erythematosus is modified by estrogens. Lupus. 2008; 17: 1086-95.

7. Doria A, Ghirardello A, Iaccarino L, et al. Pregnancy, cytokines, and disease activity in systemic lupus erythematosus. Arthritis Rheum. 2004; 51: 989-95.

8. Ostensen M, Forger F, Villiger PM. Cytokines and pregnancy in rheumatic disease. Ann N Y Acad Sci. 2006; 1069: 353-63.

9. Doria A, Cutolo M, Ghirardello A, et al. Steroid hormones and disease activity during pregnancy in systemic lupus erythematosus. Arthritis Rheum. 2002; 47: 202-9.

10. Petri M, Howard D, Repke J. Frequency of lupus flare in pregnancy. The Hopkins Lupus Pregnancy Center experience. Arthritis Rheum. 1991; 34: 1538-45.

11. Tincani A, Bompane D, Danieli E, Doria A. Pregnancy, lupus and antiphospholipid syndrome (Hughes syndrome). Lupus. 2006; 15: 156-60.

12. Hochberg MC. Updating the American College of Rheumatology revised criteria for the classification of systemic lupus erythematosus. Arthritis Rheum. 1997; 40: 1725.

13. Witter FR. Management of the high-risk lupus pregnant patient. Rheum Dis Clin North Am. 2007; 33: 253-65.

14. Griffiths B, Mosca M, Gordon C. Assessment of patients with systemic lupus erythematosus and the use of lupus disease activity indices. Best Pract Res Clin Rheumatol. 2005; 19: 685-708.

15. Olesinska M, Wiesik-Szewczyk E, Chwalinska-Sadowska H. Evaluation of systemic lupus erythematosus activity during pregnancy. Pol Arch Med Wewn. 2007; 117: 312-6.

16. Toedeter G, Hayden K, Wagner C, Brodmerkel C. Simultaneous detection of eight analytes in human serum by two commercially available platforms for multiplex cytokine analysis. Clin Vaccina Immunol. 2008; 15: 42-8.

17. Peeva E, Zouali M. Spotlight on the role of hormonal factors in the emergence of autoreactive B-lymphocytes. Immunol Lett. 2005; 101: 123-43.

18. Cohen-Solal JF, Jeganathan V, Grimaldi CM, et al. Sex hormones and SLE: influencing the fate of autoreactive B cells. Curr Top Microbiol Immunol. 2006; 305: 67-88.

19. Piccinni MP, Giudizi MG, Biagiotti R, et al. Progesterone favors the development of human $\mathrm{T}$ helper cells producing Th2-type cytokines and promotes both IL-4 production and mem- brane CD30 expression in established Th1 cell clones. J Immunol. 1995; 155: 128-33.

20. Canellada A, Blois S, Gentile T, Margni Idehu RA. In vitro modulation of protective antibody responses by estrogen, progesterone and interleukin-6. Am J Reprod Immunol. 2002; 48: 334-43.

21. Diehl S Rincon M. The two faces of IL-6 on Th1/Th2 differentiation. Mol Immunol. 2002; 39: 531-6.

22. de Waal Malefyt R, Yssel H, de Vries JE. Direct effects of IL-10 on subsets of human CD4+ T cell clones and resting T cells. Specific inhibition of IL-2 production and proliferation. J Immunol. 1993; 150: 4754-65.

23. Hagiwara E, Gourley MF, Lee S, Klinman DK. Disease severity in patients with systemic lupus erythematosus correlates with an increased ratio of interleukin-10: interferongamma-secreting cells in the peripheral blood. Arthritis Rheum. 1996; 39: 379-85.

24. Horwitz DA, Gray JD, Behrendsen SC, et al. Decreased production of interleukin-12 and other Th1-type cytokines in patients with recent-onset systemic lupus erythematosus. Arthritis Rheum. 1998; 41: 838-44.

25. Chun HY, Chung JW, Kim HA, et al. Cytokine IL-6 and IL-10 as biomarkers in systemic lupus erythematosus. J Clin Immunol. 2007; 27 : 461-6.

26. Stuart RA, Littlewood AJ, Maddison PJ, Hall ND. Elevated serum interleukin-6 levels associated with active disease in systemic connective tissue disorders. Clin Exp Rheumatol. 1995; 13: 17-22.

27. Lacki JK, Samborski W, Mackiewicz SH. Interleukin-10 and interleukin-6 in lupus erythematosus and rheumatoid arthritis, correlations with acute phase proteins. Clin Rheumatol. 1997; 16: 275-8.

28. Park YB, Lee SK, Kim DS, et al. Elevated interleukin-10 levels correlated with disease activity in systemic lupus erythematosus. Clin Exp Rheumatol. 1998; 16: 283-8.

29. Mohan AK, Edwards ET, Cote TR, et al. Drug-induced systemic lupus erythematosus and TNF-alpha blockers. Lancet. 2002; 360: 646-6.

30. Herrera-Esparza R, Barbosa-Cisneros O, Villalobos-Hurtado R, Avalos-Diaz E. Renal expression of IL-6 and TNF-alpha genes in lupus nephritis. Lupus. 1998; 7: 154-8.

31. Zampieri S, Alaibac M, Iaccarino L, et al. Tumour necrosis factor alpha is expressed in refractory skin lesions from patients with subacute cutaneous lupus erythematosus. Ann Rheum Dis. 2006; 65: 545-8.

32. Aringer M, Graninger WB, Steiner G, Smolen JS. Safety and efficacy of tumor necrosis factor alpha blockade in systemic lupus erythematosus: an open-label study. Arthritis Rheum. 2004; 50: 3161-9. 
33. Torricelli M, Bellisai F, Novembri R, et al. High levels of maternal serum IL-17 and activin $\mathrm{a}$ in pregnant women affected by SLE. Am J Reprod Immunol. 2011; 66: 84-9.

34. Muñoz-Valle JF, Vazquez-Del Mercado M, Garcia-Iglesias T, et al. T(H)1/T(H)2 cytokine profile, metalloprotease- 9 activity and hormonal status in pregnant rheumatoid arthritis and systemic lupus erythematosus patients. Clin Exp Immunol. 2003; 131: 377-84.

35. Ruiz-Irastorza G, Lima F, Alves J, et al. Increased rate of lupus flare during pregnancy and the puerperium: a prospective study of 78 pregnancies. Br J Rheumatol. 1996; 35: 133-8.

36. Clowse ME, Magder LS, Witter F, Petri M. The impact of increased lupus activity on obstetric outcomes. Arthritis Rheum. 2005; 52: 514-21.

37. Iizasa H, Matsushima K. IL-8/CXCL8. In:
Cytokine Reference 2000; vol1 2nd ed, 1062. Eds. Oppenheim JJ, Feldman M, Durum SK, Hirano T, Vilcek J, Nicola NA. San Diego: Academic Press.

38. Jovanoìc M, Stefanoska I, Radojcic L, Vìcovac L. Interleukin-8 (CXCL8) stimulates trophoblast cell migration and invasion by increasing levels of matrix metalloproteinase (MMP) and MMP9 and integrins $\alpha 5$ and $\beta 1$. Reprod Res. 2010; 139: 789-8.

39. Otun HA, Lash GE, Innes BA, et al. Effect of tumor necrosis factor- $\alpha$ in combination with interferon- $\gamma$ on first trimester extravillous trophoblast invasion. J Reprod Immunol. 2011; 88: 1-11.

40. Mulla MJ, Brosens JJ, Chamley LW, et al. Antiphospholipid antibodies induce a pro-inflammatory response in first trimester trophoblast via the TLR4/MyD88 pathway. Am J Reprod Immunol. 2009; 62: 96-111. 